\title{
Case Study: Providing Nutritional Support to an Ultraendurance Runner in Preparation for a Self-Sufficient Multistage Ultramarathon: Rationed Versus Full Energy Provisions
}

\author{
Rebekah Alcock, BND(Hon); Alan McCubbin, BND; Vera Camões-Costa, PhD; Ricardo J.S. Costa, PhD \\ From Sports Nutrition, Australian Institute of Sport, Australian Sports Commission, Bruce, Australia (Ms Alcock); the Department of Nutrition, \\ Dietetics \& Food, Monash University, Victoria, Australia (Mr McCubbin and Drs Camões-Costa and Costa); and the Health \& Aging Research \\ Group, Swinburne University of Technology, Victoria, Australia (Dr Camões-Costa).
}

\begin{abstract}
To assess the impact of rationed versus full estimated energy provisions on markers of physiological strain in response to a simulated $250 \mathrm{~km}$ multistage ultramarathon (MSUM), on two separate occasions, the

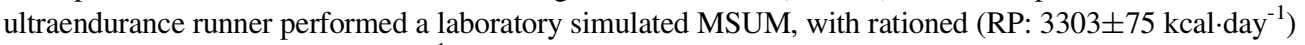
and full (FP: $7156 \pm 359 \mathrm{kcal}^{-\mathrm{day}^{-1}}$ ) provisions. Total daily energy expenditure was determined using dual-method indirect calorimetry. Resting metabolic rate, iDXA, and body water were measured at baseline, day 3, and post-MSUM. Blood, urine, and feces were collected, and mood state was measured, $\mathrm{d} 1$ to 5 (before and after running) to determine various physiological strain indices. Heart rate, RPE, thermal comfort, gastrointestinal symptoms, and non-protein oxidation rates were measured every 30 min during running. Data were analyzed using single-subject design analysis and interpreted using Cohen's effect size. Energy expenditure was lower on RP $\left(6943 \pm 145 \mathrm{kcal}^{\left.-\mathrm{day}^{-1}\right)}\right.$ than FP $\left(7486 \pm 143 \mathrm{kcal}^{\left.-\mathrm{day}^{-1}\right)}\right.$ (Cohen's $\delta=-3.1$ ). More pronounced exertional strain (RPE $\delta=1.2$, thermal conform $\delta=0.6$, rectal temperature $\delta=1.0$, and plasma cortisol concentration $\delta=1.7$ ) was observed on RP as the MSUM progressed. Total carbohydrate and fat oxidation during running decreased $\left(0.76\right.$ vs. $\left.1.82 \mathrm{~g} \cdot \mathrm{min}^{-1} ; \delta=-3.9\right)$ and increased (0.91 vs. $0.54 \mathrm{~g} \cdot \mathrm{min}^{-1} ; \delta=3.7$ ), respectively, more profoundly on RP as the MSUM progressed. Gastrointestinal symptoms were modestly lower in RP $(\delta=-0.26)$. Exercise-induced leukocytosis, cytokinaemia, and neutrophil responses were higher on RP. Iron status markers were trivial. Higher mood disturbance and fatigue were reported on RP. The ultraendurance runner presented greater physiological and psychophysiological disturbances, in response to a laboratory simulated MSUM, on rationed energy provisions, despite the lighter pack-weight.
\end{abstract}

Keywords: macronutrients, hydration, gastrointestinal, oxidation, thermoregulation, cytokines

\section{Introduction}

Multistage ultramarathon (MSUM) event and participation numbers have risen exponentially in the last decade. ${ }^{1,2}$ Such events are associated with self-sufficiency criteria (eg, carrying all clothing, equipment, and

Corresponding author: Dr. Ricardo J.S. Costa, Department of Nutrition, Dietetics \& Food, Monash University, Level 1, 264 Ferntree Gully road, Notting Hill, 3168 Victoria, Australia. Telephone: 0061 411568353; e-mail: ricardo.costa@monash.edu.

Submitted for publication November 2017

Accepted for publication June 2018. food), involving consecutive days of loaded (eg, packweight $5-15 \mathrm{~kg}$ ) running in extreme environments (eg, $\leq 0^{\circ} \mathrm{C}$ to $\geq 30^{\circ} \mathrm{C}$ ambient temperature, and altitude of $>3000 \mathrm{~m}$ above sea level) and harsh terrains (eg, arctic, mountain, desert, and rainforest). To reduce packweight, ultraendurance runners often restrict food volume at the expense of caloric intake, while depending on

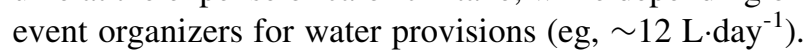
Moreover, there has been a recent trend towards ultraendurance runners predominantly relying on their reserve endogenous energy substrate (eg, fat stores and ketone bodies), and attempting to enhance their utilization 
through various dietary manipulation strategies, to support event completion. ${ }^{3-5}$ Thus, MSUM participants frequently abstain from carrying adequate caloric provisions, with focus on carrying the event's minimal requirements (eg, $\sim 2000 \mathrm{kcal} \cdot \mathrm{day}^{-1}$ : 4Deserts and BeyondTheUltimate). As such, compromised energy (and nutritional) intake, respective to task, has consistently been observed throughout MSUM participation. ${ }^{6,7}$ Energy (and nutritional) deficits, within an endurance exercise model, have been linked to stress hormone (eg, cortisol), immune (eg, neutrophil function and cytokine profile), and iron status disturbances; and in addition, poorer recovery and greater perception of fatigue. .,8-11 $^{-1}$ To date, the relationship between pack-weight, energy expenditure, energy and nutritional requirements, optimal dietary programming and provisions during self-sufficient MSUM has not been thoroughly investigated. This is largely due to multiple confounding factors (eg, variations in subject demographics, course topography, environmental conditions, dietary habits, compliance) present in attempting to implement a dietary intervention within an event.

During MSUM competition, especially in hot ambient conditions (ie, $\geq 30^{\circ} \mathrm{C}$ ), there is a tendency for ultraendurance runners to over-drink, placing them at risk of either asymptomatic or symptomatic exercise-associated hyponatremia. ${ }^{12-13}$ It is, therefore, important to determine how rationed and full energy provisions alters fluid replacement or changes in hydration status along MSUM. Additionally, gastrointestinal symptoms are a predominant feature of ultramarathon running. Whereby, $85 \%$ and $96 \%$ incidence of severe symptoms have been reported by an ultramarathon participant cohort in response to a $230 \mathrm{~km}$ multistage and $161 \mathrm{~km}$ single-stage ultramarathon event, respectively. ${ }^{14,15}$ The causes appear to be multi-factorial, but primarily stem from exerciseinduced gastrointestinal syndrome, ${ }^{16}$ and is a key barrier to ultraendurance runners consuming sufficient foods and fluids to meet energy and nutritional requirements throughout MSUM competition. ${ }^{14}$ It is currently unknown if dietary planning to meet total daily, during running, and recovery nutritional requirements will exacerbate symptoms during a period of gastrointestinal vulnerability, or can be realistically consumed due to the effects of gastrointestinal symptoms.

With these factors in mind, the current case study aimed to determine the impact of different degrees of energy provisions (ie, rationed $v s$ full), and subsequent changes in pack-weight, on varying physiological parameters of an ultraendurance runner during a laboratory simulated MSUM, in order to inform preparation and dietary planning for a desert based multiday ultra-challenge. It was hypothesized that rationed provisions would result in greater perturbations to the physiological and psychophysiological parameters measured, compared with full provisions.

\section{Methods \\ CASE-RUNNER AND MULTISTAGE ULTRAMARATHON SIMULATION}

After ethics approval from Monash University human research ethics committee (CF14/1539 - 2014001865), a healthy non-heat acclimatized male ultraendurance runner provided informed consent and volunteered to complete two laboratory simulated MSUM. He reported 5 y of ultraendurance running experience in single and multistage (ie, self-sufficient and semi-supported) events, in desert and mountainous terrain, with distances ranging from 42 to $5330 \mathrm{~km}$; and was accustomed to rationing food provision aimed at reduce carrying weight. The subject's training consisted of approximately $150 \mathrm{~km} \cdot \mathrm{wk}^{-1}$ running, and was following a dietary regime in accordance with consensus guidelines. ${ }^{17}$ Using an A-B singlesubject design, on 2 separate randomized occasions, separated by $3 \mathrm{mo}$, during the winter-spring season, in which ambient temperature was consistently $\leq 20^{\circ} \mathrm{C}$, the subject undertook the MSUM simulations with rationed (RP) and full energy provisions (FP). The MSUM simulation protocols consisting of running $50 \mathrm{~km}$ with a loaded pack, on a motorized treadmill (Forma Run 500, Technogym, Seattle, WA, USA), for 5 consecutive days, totaling $250 \mathrm{~km}$, in warm ambient conditions (mean $\pm \mathrm{SD}$ : RP $29.2 \pm 0.8^{\circ} \mathrm{C}$ and $32 \pm 2 \%$ relative humidity (RH), FP $29.4 \pm 1.0$ and $32 \pm 4 \% \mathrm{RH}$, dual-fan wind speed of $10.6 \mathrm{~km} \cdot \mathrm{h}^{-1}$ ), and exercise intensity targeting $55 \%$ $\dot{V} \mathrm{O}_{2 \max }\left(8 \mathrm{~km} \cdot \mathrm{h}^{-1}\right)$ (Figure 1). If the subject was unable to maintain the prescribed running speed, ad libitum decrease in treadmill speed was allowed to $6 \mathrm{~km} \cdot \mathrm{h}^{-1}$. Total walking time was documented and reported accordingly. Considering the course topography from a number of MSUM events reaches $>3000 \mathrm{~m}$ altitude (eg, transAlpine and trans-Rockies), on this occasion, the current case study did not expose the subject to these conditions, since the magnitude of altitude was not of relevance in preparation for the subject's desert-based ultrachallenge ( $<1000$ m altitude course).

Two weeks before each laboratory simulated MSUM, the subject undertook a standardized initial assessment, which included anthropometrical measures and an incremental exercise test to volitional exhaustion, as previously reported. ${ }^{9}$ From the $\mathrm{VO}_{2}$-work rate relationship, the treadmill speed at $55 \% \dot{V O}_{2}$ max and $1 \%$ gradient was extrapolated and verified. Thereafter, on a separate day, the subject was familiarized with the daily protocol, by running for $50 \mathrm{~km}$ with a loaded pack in warm ambient 
Initial assessment (anthropometry and $\dot{\nu}_{2 \mathrm{max}}$ )

1 One week

Familiarisation

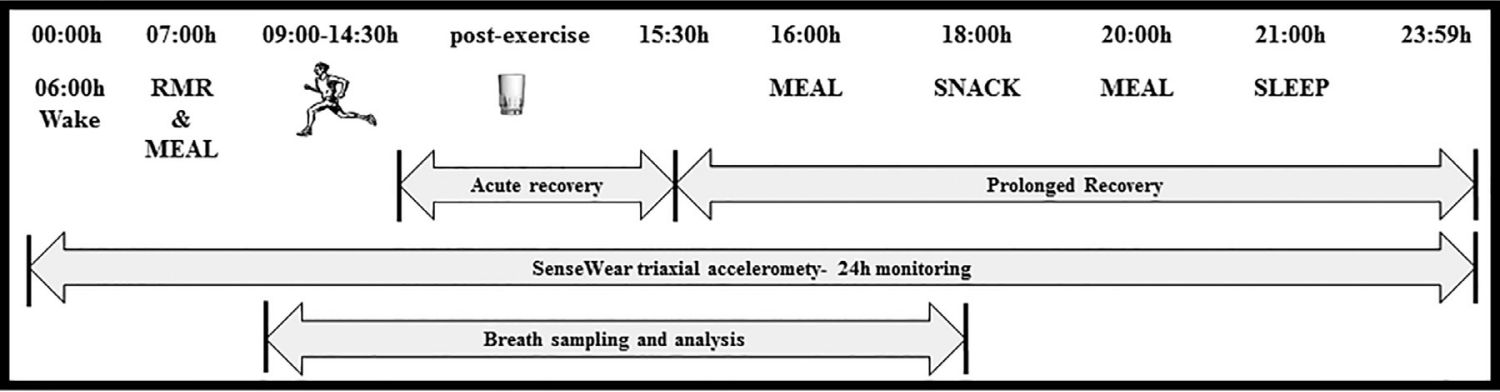

$\checkmark$ One week

Simulation protocol- Days 1 to 5

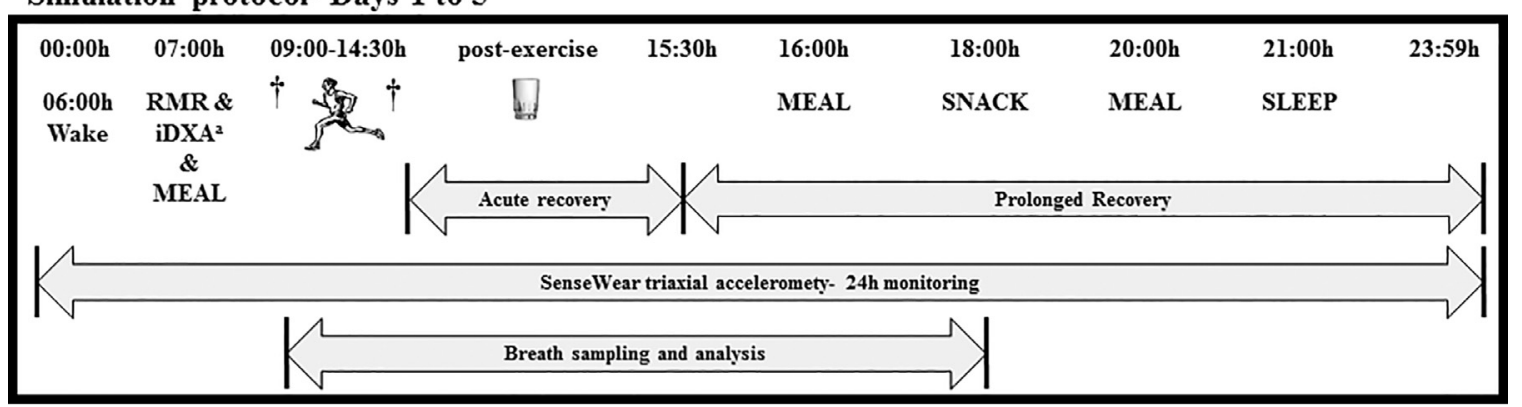

Figure 1. Full schematic description of the laboratory simulated multistage ultramarathon (MSUM) protocol. $\dagger$ Antecubital venous blood sample, nude body mass, and gastrointestinal symptoms; ${ }^{a}$ morning fasted resting metabolic rate (RMR) and dual-energy X-ray absorptiometry (iDXA) baseline, day 3 of running, and post-MSUM (day after completion). MEAL allocations provided by BASE Essentials (BASE Facility, Monash University, Notting Hill, Victoria, Australia) at rationed provisions (RP) and full provisions (FP).

$50 \mathrm{~km}$ running targeting $55 \% \mathrm{VO}_{2}$ max in $29.3 \pm 0.9^{\circ} \mathrm{C}$ and $32 \pm 3 \% \mathrm{RH}$, including respective pack-weight. Carbohydrate intake provided at total carbohydrate oxidation rate at point of stress muscle glycogen stores (2:1 glucose to fructose in $10 \%$ water volume $(w / v)$, as identified through the familiarization protocol (RP $37.5 \mathrm{~g} \cdot \mathrm{h}^{-1}$ and FP $75.0 \mathrm{~g} \cdot \mathrm{h}^{-1}$ ), consumed evenly every $20 \mathrm{~min}$, and any additional water intake ad libitum. Heart rate, RPE, thermal comfort rating, rectal temperature $\left(\mathrm{T}_{\mathrm{re}}\right)$, and blood glucose were measured, and breath-by-breath sampling by Vmax Encore PFT system and single breath sample were collected every 30 min during running.

Recovery beverage consumed within $30 \mathrm{~min}$ after running cessation, which contained $1.2 \mathrm{~g} \cdot \mathrm{kg}^{-1}$ carbohydrate and $0.4 \mathrm{~g} \cdot \mathrm{kg}^{-1}$ protein, in a $10 \%$ carbohydrate water volume $(w / v)$.

conditions $\left(29.9 \pm 0.8^{\circ} \mathrm{C}\right.$ and $\left.29 \pm 3 \% \mathrm{RH}\right)$, in which estimated total daily energy expenditure (TDEE) and nonprotein oxidation rates during running were determined by indirect calorimetry (Vmax Encore PFT System, CareFusion, Yorba Linda, CA, USA), as previously reported. ${ }^{18,19}$ TDEE was verified against triaxial accelerometry (SenseWear 7.0, Bodymedia Inc. Pittsburg, PA USA) (coefficient of variation (CV): $4.4 \%$ )..$^{20,21}$ During each respective laboratory simulated MSUM the subject wore a loaded pack which included a constant weight $(5.1 \mathrm{~kg})$ portion to represent clothing and equipment, and a variable weight portion to represent food provisions and consumption along the simulated MSUM. From a practical and control perspective, pack-weight and volume were comprehensively regulated using fine grade sand, in which the author acknowledge would not reflect the precise volumetric dimensions of clothing, equipment, and food in a real-world scenario.

\section{DIETARY INTERVENTION}

Dietary intervention programming for RP and FP used BASE Essentials (BASE Facility, Monash University, 
Table 1. Energy expenditure, dietary intake, and body composition changes of an ultra-endurance runner during a $250 \mathrm{~km}\left(50 \mathrm{~km} \cdot \mathrm{d}^{-1}\right.$ for $\left.5 \mathrm{~d}\right)$ laboratory simulated multistage ultramarathon (MSUM) in warm ambient conditions in response to rationed (RP) and full (FP) provision.

\begin{tabular}{|c|c|c|c|c|c|c|c|c|c|c|c|}
\hline & \multicolumn{5}{|c|}{ Rationed Provisions (RP) } & \multicolumn{5}{|c|}{ Full Provisions (FP) } & \multirow{2}{*}{$\begin{array}{l}\text { Cohen's } \delta \\
R T \text { vs FT }\end{array}$} \\
\hline & Day 1 & Day 2 & Day 3 & Day 4 & Day 5 & Day 1 & Day 2 & Day 3 & Day 4 & Day 5 & \\
\hline $\mathrm{RMR}^{a}$ & 1728 & - & 1776 & - & 1891 & 1827 & - & 1752 & - & 1974 & -0.5 \\
\hline TDEE $\left(\mathrm{kcal} \cdot \mathrm{d}^{-1}\right)$ & 7194 & 6933 & 6845 & 6849 & 6896 & 7255 & 7544 & 7580 & 7605 & 7446 & -3.1 \\
\hline TDEE $\left(\mathrm{kcal} \cdot \mathrm{kg}^{-1} \cdot \mathrm{d}^{-1}\right)$ & 91 & 88 & 88 & 87 & 88 & 91 & 96 & 95 & 96 & 93 & -2.7 \\
\hline resting (kcal) & 1962 & 1993 & 2030 & 1887 & 2085 & 2059 & 2279 & 2181 & 2368 & 2232 & -2.1 \\
\hline running (kcal) & 5232 & 4940 & 4815 & 4962 & 4811 & 5196 & 5265 & 5399 & 5237 & 5214 & -1.7 \\
\hline running $\left(\mathrm{kcal} \cdot \mathrm{h}^{-1}\right)$ & 837 & 790 & 770 & 794 & 770 & 831 & 842 & 864 & 838 & 834 & -1.7 \\
\hline Food weight (kg) & 4.2 & 3.4 & 2.5 & 1.7 & 0.8 & 9.0 & 7.2 & 5.3 & 3.6 & 1.8 & -1.2 \\
\hline Total pack-weight (kg) & 9.2 & 8.4 & 7.5 & 6.7 & 5.8 & 14.0 & 12.2 & 10.3 & 8.6 & 6.8 & -1.2 \\
\hline TEI $\left(\mathrm{kcal} \cdot \mathrm{d}^{-1}\right)^{c}$ & 3191 & 3341 & 3341 & 3341 & 3965 & 6620 & 7339 & 7339 & 7339 & 4658 & -3.7 \\
\hline carbohydrate $\left(\mathrm{g} \cdot \mathrm{d}^{-1}\right)^{d}$ & 555 & 566 & 566 & 566 & 582 & 1122 & 1230 & 1230 & 1230 & 868 & -5.1 \\
\hline protein $\left(\mathrm{g} \cdot \mathrm{d}^{-1}\right)^{e}$ & 110 & 114 & 114 & 114 & 130 & 209 & 220 & 220 & 220 & 254 & -7.5 \\
\hline fat $\left(g \cdot d^{-1}\right)^{f}$ & 59 & 69 & 69 & 69 & 69 & 144 & 171 & 171 & 171 & 74 & -2.6 \\
\hline sodium $\left(\mathrm{g} \cdot \mathrm{d}^{-1}\right)$ & 4.9 & 4.7 & 4.7 & 4.7 & 4.3 & 8.8 & 8.5 & 8.5 & 8.5 & 4.8 & -2.6 \\
\hline water $\left(\mathrm{L} \cdot \mathrm{d}^{-1}\right)^{g}$ & 4.0 & 4.6 & 4.5 & 4.9 & 4.6 & 4.1 & 4.6 & 4.3 & 4.5 & 4.4 & 0.4 \\
\hline Resting nude body mass $(\mathrm{kg})^{a}$ & 78.7 & 78.5 & 78.1 & 78.3 & 78.2 & 80.1 & 79.6 & 79.8 & 78.9 & 79.9 & $0.4^{\dagger}$ \\
\hline Body fat mass $(\%)^{a}$ & 21.3 & - & 20.8 & - & 19.3 & 15.7 & - & 15.5 & - & 15.6 & $-1.0^{\dagger}$ \\
\hline Bone mineral content $(\mathrm{g})^{a}$ & 3249 & - & 3284 & - & 3256 & 3232 & - & 3247 & - & 3239 & $0.5^{\dagger}$ \\
\hline Bone density $\left(\mathrm{g} \cdot \mathrm{cm}^{2}\right)^{a}$ & 1.333 & - & 1.326 & - & 1.316 & 1.363 & - & 1.333 & - & 1.341 & $-1.7^{\dagger}$ \\
\hline Total body water $(\% \mathrm{BM})^{a}$ & 58.9 & - & 58.0 & - & 60.9 & 59.2 & - & 60.6 & - & 60.1 & $-0.3^{\dagger}$ \\
\hline Extracellular water $(\% \mathrm{BM})^{a}$ & 22.5 & - & 22.1 & - & 24.4 & 23.6 & - & 23.9 & - & 24.1 & $0.2^{\dagger}$ \\
\hline Intracellular water $(\% \mathrm{BM})^{a}$ & 35.7 & - & 35.2 & - & 35.8 & 34.9 & - & 36.1 & - & 35.3 & $-1.7^{\dagger}$ \\
\hline Plasma volume change (\%) & 0.0 & 8.0 & 14.3 & 15.1 & 19.0 & 0.0 & 4.4 & 5.0 & 4.4 & 5.7 & $1.0^{\dagger}$ \\
\hline
\end{tabular}

(continued on next page) 
Table 1. (Continued)

\begin{tabular}{|c|c|c|c|c|c|c|c|c|c|c|}
\hline & \multicolumn{5}{|c|}{ Rationed Provisions (RP) } & \multicolumn{5}{|c|}{ Full Provisions (FP) } \\
\hline & Day 1 & Day 2 & Day 3 & Day 4 & Day 5 & Day 1 & Day 2 & Day 3 & Day 4 & Day 5 \\
\hline Breakfast & \multicolumn{5}{|c|}{$\begin{array}{l}\text { Day 1: Ad libitum } \\
\text { Day } 2 \text { to 5: Six Vitabrits with } 300 \mathrm{~mL} \text { skimmed milk, } 300 \mathrm{~mL} \text { orange juice, } \\
\text { and one PowerPacket*. }\end{array}$} & \multicolumn{5}{|c|}{$\begin{array}{l}\text { Day 1: Ad libitum } \\
\text { Day } 2 \text { to 5: Twelve Vitabrits with } 600 \mathrm{~mL} \text { skimmed milk, } \\
600 \mathrm{~mL} \text { orange juice with maltodextrin, and two } \\
\text { PowerPacket*. }\end{array}$} \\
\hline During running & \multicolumn{5}{|c|}{$\begin{array}{l}\text { Exogenous } \mathrm{CHO}^{h}: \text { Modified (maltodextrin) Pro4mance Produrance with } \\
\text { and potato crisp }(75 \mathrm{~g}) \text {. }\end{array}$} & \multicolumn{5}{|c|}{$\begin{array}{l}\text { Exogenous } \mathrm{CHO}^{h}: \text { Modified (maltodextrin) Pro4mance Pro- } \\
\text { durance with and potato crisp }(80 \mathrm{~g}) \text {. }\end{array}$} \\
\hline $\begin{array}{l}\text { Acute recovery } \\
(\leq 1 \mathrm{~h} \text { post-exercise })\end{array}$ & \multicolumn{5}{|c|}{$\begin{array}{l}\text { Recovery beverage }{ }^{i}: \text { Modified (milk powder and maltodextrin) Pro4mance } \\
\text { Procover. }\end{array}$} & \multicolumn{5}{|c|}{$\begin{array}{l}\text { Recovery beverage }^{i} \text { : Modified (milk powder and maltodex- } \\
\text { trin) Pro4mance Procover. }\end{array}$} \\
\hline $\begin{array}{l}\text { Prolonged recovery } \\
\text { ( } \geq 1 \mathrm{~h} \text { post-exercise })\end{array}$ & \multicolumn{5}{|c|}{$\begin{array}{l}\text { Day } 1 \text { to 4: One ExtremeMeal*. } \\
\text { Day 5: Ad libitum. }\end{array}$} & \multicolumn{5}{|c|}{$\begin{array}{l}\text { Day } 1 \text { to } 4: \text { Two Ex } \\
\text { ified (milk powder } \\
\text { Day 5: Ad libitum }\end{array}$} \\
\hline Evening meal/snack & \multicolumn{5}{|c|}{$\begin{array}{l}\text { Day } 1 \text { to 4: Modified (milk powder) Pro4mance Procover. } \\
\text { Day 5: Ad libitum. }\end{array}$} & \multicolumn{5}{|c|}{$\begin{array}{l}\text { Day } 1 \text { to 4: Modified (milk powder) Pro4mance Procover. } \\
\text { Day 5: Ad libitum. }\end{array}$} \\
\hline Additional water & \multicolumn{5}{|c|}{ Ad libitum. } & \multicolumn{5}{|c|}{ Ad libitum. } \\
\hline
\end{tabular}

*BASE Essentials (BASE Facility, Monash University, Notting Hill, Victoria, Australia). PowerPacket portion (mean \pm SD): energy $679 \pm 44$ kcal, carbohydrate $107 \pm 7$ g, protein $29 \pm 1$ g, fat $15 \pm 3 \mathrm{~g}$, sodium $314 \pm 48 \mathrm{mg}$, with the addition of $300 \mathrm{~mL}$ hot water; ExtremeMeals portion (mean $\pm \mathrm{SD}$ ): energy $758 \pm 86 \mathrm{kcal}$, carbohydrate $102 \pm 12 \mathrm{~g}$, protein $29 \pm 6 \mathrm{~g}$, fat $26 \pm 6 \mathrm{~g}$, sodium $1159 \pm 283 \mathrm{mg}$, with the addition of $300 \mathrm{~mL}$ hot water.

${ }^{a}$ Morning fasted measurement at baseline, Day 3 of running, and post-MSUM;

${ }^{b}$ Running at $55 \% \mathrm{VO}_{2} \max \left(8 \mathrm{~km} \cdot \mathrm{h}^{-1}\right)$, however if the subject was unable to maintain the prescribed running speed, ad libitum decrease in treadmill speed was allowed to $6 \mathrm{~km} / \mathrm{h}$;

${ }^{c}$ Mean energy intake: RP $42 \mathrm{kcal} \cdot \mathrm{kg} \cdot \mathrm{d}^{-1}$ and FP $92 \mathrm{kcal} \cdot \mathrm{kg} \cdot \mathrm{d}^{-1}$ in a $12 \%$ protein, $67 \%$ carbohydrate, and $21 \%$ fat contribution;

${ }^{d}$ Mean carbohydrate intake (includes exogenous intake during running): RP $7.2 \mathrm{~g} \cdot \mathrm{kg} \cdot \mathrm{d}^{-1}$ and FP $15 \mathrm{~g} \cdot \mathrm{kg} \cdot \mathrm{d}^{-1}$;

${ }^{e}$ Mean protein intake: RP $1.4 \mathrm{~g} \cdot \mathrm{kg} \cdot \mathrm{d}^{-1}$ and FP $2.7 \mathrm{~g} \cdot \mathrm{kg} \cdot \mathrm{d}^{-1}$

${ }^{f}$ Mean fat intake: RP $0.9 \mathrm{~g} \cdot \mathrm{kg} \cdot \mathrm{d}^{-1}$ and FP $2.1 \mathrm{~g} \cdot \mathrm{kg} \cdot \mathrm{d}^{-1}$

${ }^{g}$ Mean water intake: RP $57 \mathrm{~mL} \cdot \mathrm{kg} \cdot \mathrm{d}^{-1}$ and FP $55 \mathrm{~mL} \cdot \mathrm{kg} \cdot \mathrm{d}^{-1}$;

${ }^{h}$ Exogenous CHO intake during running: RP $37.5 \mathrm{~g} \cdot \mathrm{h}^{-1}(12.5 \mathrm{~g} / 20 \mathrm{~min})$, and FP $75.0 \mathrm{~g} \cdot \mathrm{h}^{-1}(25.0 \mathrm{~g} / 20 \mathrm{~min})$, in a $2: 1$ glucose-fructose ratio $10 \% \mathrm{w} / \mathrm{v}$ with the addition of potato crisps.

${ }^{i}$ Dairy milk based recovery beverage: RP $0.6 \mathrm{~g} \cdot \mathrm{kg}^{-1}$ carbohydrate and $0.2 \mathrm{~g} \cdot \mathrm{kg}^{-1}$ protein, and $1.2 \mathrm{~g} \cdot \mathrm{kg}^{-1}$ carbohydrate and $0.4 \mathrm{~g} \cdot \mathrm{kg}^{-1}$ protein, in a $10 \%$ carbohydrate $w / \nu$.

${ }^{\dagger}$ Relative change from day 1 of running (pre-running). RMR: resting metabolic rate, TDEE: total daily energy expenditure, TEI: total energy intake, BM: body mass. Cohen's $\delta$ reflects the standardized measurement of effect size and direction of difference (decrease or increase) between the overall mean (day 1 to day 5) values of RP vs FP. 
Notting Hill, Victoria, Australia) dehydrated and freezedried meal range, and dehydrated based snacks (Table 1). Intake was monitored via a compliance log. The macronutrient content was prescribed in accordance with consensus guidelines, ${ }^{17}$ and targeted at achieving carbohydrate and protein intake at $\geq 12 \mathrm{~g} \cdot \mathrm{kg} \cdot \mathrm{d}^{-1}$ and $\geq 1.3 \mathrm{~g} \cdot \mathrm{kg} \cdot \mathrm{d}^{-1}$, respectively, on FP. Fat energy (predominantly from monounsaturated sources, such as extra virgin olive oil and macadamia nut oil) was added to ensure the requirements for TDEE were met. Food provisions were halved for RP, and the packweight was adjusted to reflect the food volume to be consumed.

Carbohydrate intake during running was established from the total carbohydrate oxidation rates at the point of stressed muscle glycogen stores ( $\geq 3 \mathrm{~h}$ ), at the simulation running speed, determined during the familiarization (RP $37.5 \mathrm{~g} \cdot \mathrm{h}^{-1}$, FP $\left.75.0 \mathrm{~g} \cdot \mathrm{h}^{-1}\right){ }^{20}$ A carbohydrate solution (2:1 glucose-fructose, $10 \%$ water volume $(w / v)$; Produrance, Pro4mance Global Pty Ltd, Bayswater, Victoria, Australia), and savory solid foods to avoid oral fatigue, were used to achieve hourly carbohydrate intake rates, and provided evenly at $20 \mathrm{~min}$ intervals. Within $30 \mathrm{~min}$ after each running bout, a commercially available recovery beverage was consumed (Procover, Pro4mance Global Pty Ltd), which contained $1.2 \mathrm{~g} \cdot \mathrm{kg}^{-1}$ carbohydrate and $0.4 \mathrm{~g} \cdot \mathrm{kg}^{-1}$ protein, in a $10 \%$ carbohydrate water volume $w / v .^{9,17,22}$ Additionally, water was provided ad libitum during the rest and running periods. Energy and macronutrient composition of dietary interventions were determined by dietary analysis software (Foodworks v7, Xyris Software, Australia), as previously reported. ${ }^{6,12,21}$

\section{SAMPLE AND DATA COLLECTION AND ANALYSIS}

The day before (baseline) the start of each laboratory simulated MSUM, the subject arrived at 0700 fasted, where resting metabolic rate (RMR) and body composition were determined by metabolic cart indirect calorimetry and dual-energy x-ray absorptiometry (iDXA, GE Lunar iDXA, GE Healthcare Lunar, Madison, Wisconsin, USA), respectively. These measures were repeated on Day 3 of running and the day after completion (postMSUM). A SenseWear armband was attached to the mid-triceps and maintained in situ throughout.

On Days 1 to 5 of running, immediately before each running bout, nude body mass was measured, followed by mid-flow urine to determine urinary ketones (Multistix10SG Urinalysis strips, Siemens Healthcare Diagnostic, USA), and venous blood sampling from an antecubital vein (ie, $6 \mathrm{~mL} 1.5 \mathrm{IU}$-heparin $\cdot \mathrm{mL}^{-1}, 4 \mathrm{~mL} 1.6 \mathrm{mg}$-EDTA $\cdot \mathrm{mL}^{-1}$, and $6 \mathrm{~mL}$ silica clot vacutainers; Becton Dickinson, Oxford,
$\mathrm{UK})$ that was processed and stored $\left(-80^{\circ} \mathrm{C}\right)$ before analysis, for determination of relevant whole blood, plasma and serum markers of stress, immunity, iron status, and gastrointestinal integrity. Additionally, before each running bout, a mid-flow fecal sample $(\sim 30 \mathrm{~g})$ was collected and immediately stored $\left(-80^{\circ} \mathrm{C}\right)$ to determine fecal calprotectin. The subject also provided a breath sample into a $250 \mathrm{ml}$ breath collection bag (Wagner Analysen Technick, Bremen, Germany) to determine breath hydrogen $\left(\mathrm{H}_{2}\right)$, and completed a Profile of Mood States (POMS) questionnaire ${ }^{23}$ and gastrointestinal symptom assessment tool ${ }^{14,19}$ before the onset of running each day. A 10-point rating scale was used to quantify self-perceived gastrointestinal symptoms (adapted from a $100 \mathrm{~mm}$ visual analogue scale), ${ }^{24,25}$ with 0 indicative of no symptoms, 1 to 4 mild symptoms, 5 to 9 severe symptoms, and 10 indicative of extreme symptoms requiring exercise cessation. Total body water, including extra- and intra-cellular water, was determined through an 8-point multifrequency bioelectrical impedance analyzer (mBCA 515, Seca, Ecomed, Hamburg, Germany), after the subject had remained lying in the supine position for at least $15 \mathrm{~min}$.

During running, heart rate, RPE, rectal temperature $\left(\mathrm{T}_{\mathrm{re}}\right)$, thermal comfort rating, gastrointestinal symptoms, and blood glucose were monitored, and a breath sample was collected every $30 \mathrm{~min}$. Breath-by-breath indirect calorimetry was used to determine $\dot{V} \mathrm{O}_{2}, \dot{V} \mathrm{CO}_{2}$ and respiratory exchange ratio. A 5-min breath-by-breath collection period every 30 min during running was applied, where the runner inserted a sealed mouthpiece orally and wore a noise clamp during the collection period. Data was subsequently used to calculate total carbohydrate and fat oxidation rates, in accordance with Péronnet and Massicotte (1991). ${ }^{26}$

Total CHO oxidation

$$
:\left(4.585 \times \dot{V} \mathrm{CO}_{2}\right)--\left(3.226 \times \dot{V} \mathrm{O}_{2}\right)
$$

Total Fat oxidation

$$
:\left(1.695 \times \dot{V} \mathrm{O}_{2}\right)--\left(1.701 \times \dot{V} \mathrm{CO}_{2}\right)
$$

For consistency, all measurements and samples were recorded and collected before carbohydrate feeding at each respective time-point. Immediately after each running bout within the laboratory simulated MSUM, nude body mass was measured, followed by blood, urine, and fecal sampling, as previously described. Gastrointestinal symptoms and POMS were also assessed in the recovery period, and breath samples were collected every $30 \mathrm{~min}$ for $4 \mathrm{~h}$.

Breath samples $(20 \mathrm{~mL})$ were analyzed in duplicate (CV $4.0 \%$ ) for $\mathrm{H}_{2}$ content using a gas-sensitive analyzer 



Figure 2. Time spent walking by an ultra-endurance runner during a $250 \mathrm{~km}\left(50 \mathrm{~km} \cdot\right.$ day $^{-1}$ for $\left.5 \mathrm{~d}\right)$ laboratory simulated multistage ultramarathon (MSUM), including respective pack-weight, with rationed (A) and full (B) provision. Cohen's $\delta=0.08$.

(Breathtracker Digital Microlyzer, Quintron, Milwaukee, Wisconsin, US). EDTA and silica clot whole blood was used to quantify whole blood counts and markers of iron status, respectively, through local pathology services (Cabrini Pathology, Malvern, Victoria, Australia). Haemoglobin and haematocrit values were used to estimate changes in plasma volume relative to Day 1 pre-running and used to correct plasma and serum variables. ${ }^{27}$ Blood glucose concentration was determined from pre- and post-running lithium heparin whole blood using a handheld glucose monitor (Accu-Chek Proforma, Roche Diagnostics, Indianapolis, Indiana, USA) (CV: 1.7\%). The remaining whole blood samples were centrifuged at $4000 \mathrm{rpm}$ for $10 \mathrm{~min}$ within $15 \mathrm{~min}$ of sample collection.
Plasma was aliquoted into $1.5 \mathrm{ml}$ micro-storage tubes and frozen at $-80^{\circ} \mathrm{C}$ until analysis. Prior to the processing and storage, $1 \mathrm{ml}$ volume of lithium heparin whole blood was bacterially challenge by adding to $50 \mu \mathrm{L}$ of $1 \mathrm{mg} \cdot \mathrm{mL}^{-1}$ bacterial stimulant ( $E$ coli derived lipopolysaccharide, Sigma, Poole, UK) within 5 min of collection and gently vortex-mixed. Samples were immediately placed in a water bath at $37^{\circ} \mathrm{C}$ for $1 \mathrm{~h}$ incubation, and further mixed by gentle inversion at $30 \mathrm{~min}$. After $1 \mathrm{~h}$ incubation, bacterially challenged samples were centrifuged at $4000 \mathrm{rpm}$ for $10 \mathrm{~min}$. Supernatant was then aspirated into $1.5 \mathrm{~mL}$ micro-storage tubes and stored at $-80^{\circ} \mathrm{C}$ for further analysis.

Plasma concentrations of interleukin (IL)-6, IL- $1 \beta$, tumour necrosis factor (TNF)- $\alpha$, IL-8, IL-10, and IL-1 

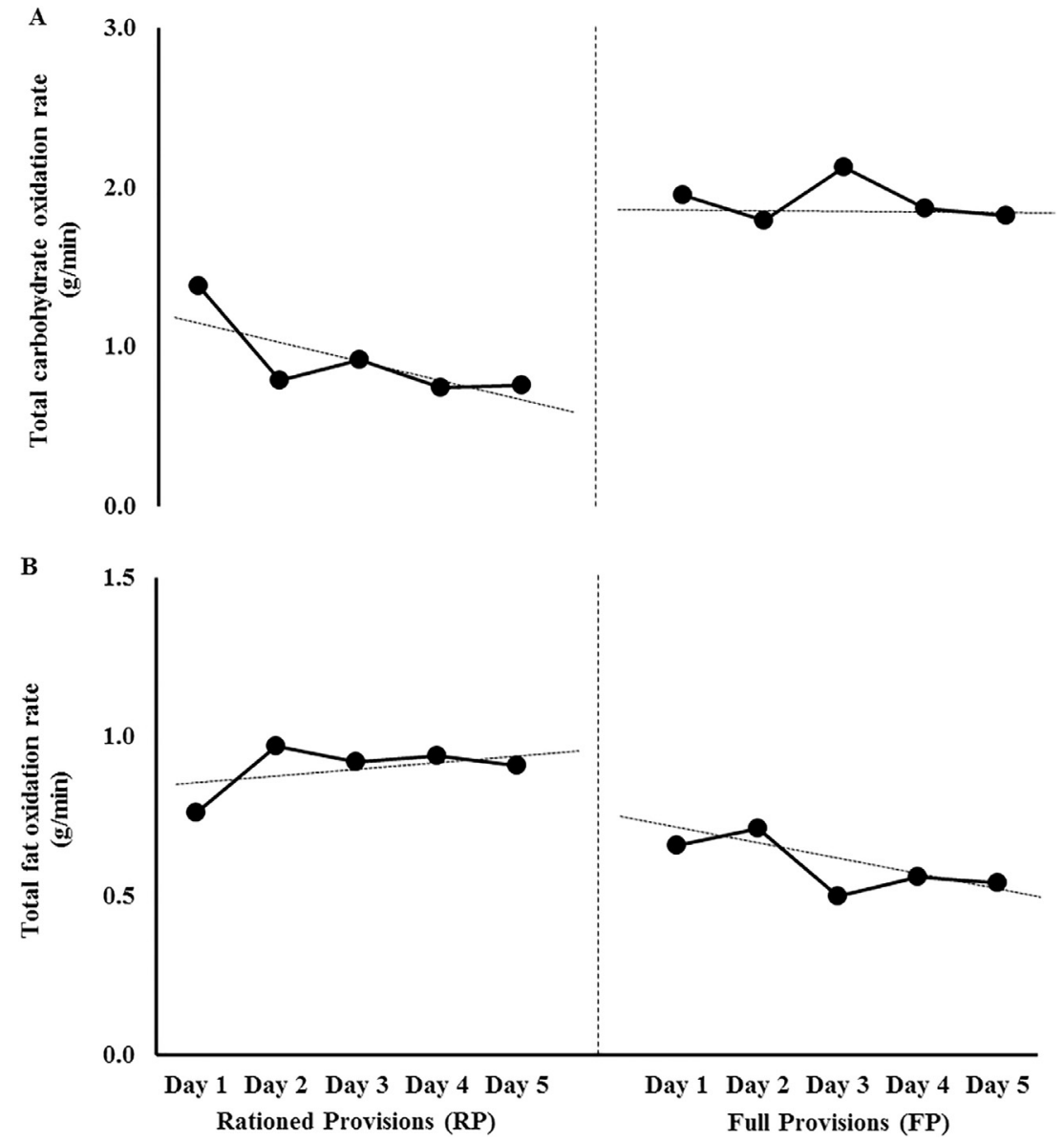

Figure 3. Total carbohydrate (A) and fat (B) oxidation rates of an ultraendurance runner during a $250 \mathrm{~km}\left(50 \mathrm{~km} \cdot \mathrm{day}^{-1}\right.$ for $\left.5 \mathrm{~d}\right)$ laboratory simulated multistage ultramarathon (MSUM), including respective pack-weight, with rationed (RP) and full (FP) provision. Split middle trend analysis for RP: decelerating trend for total carbohydrate oxidation rate, and accelerating trend for total fat oxidation rate. Split middle trend analysis for FP: no change in carbohydrate oxidation rate, and decelerating trend for total fat oxidation rate.

receptor antagonist (ra) were determined by multiplex enzyme-linked immunosorbent assay (ELISA; HCYTOMAG-60K, EMD Millipore, Darmstadt, Germany). Plasma concentrations of I-FABP (HK406, Hycult Biotech, Uden, Netherlands), cortisol (RE52061, IBL International, Hamburg, Germany), elastase (BMS269, Bender MedSystems, Vienna, Austria), and fecal concentrations of calprotectin (DE849, Demeditec, Kiel, Germany) were determined by ELISA. All variables were analysed as per manufacturer's instructions on the same day, with standards and controls on each plate, and each participant assayed on the same plate. The CVs for assay variables was $\leq 9.0 \%$. In adjunct with descriptive statistics (Day 1 to Day 5 overall mean $\pm \mathrm{SD}$, otherwise specified), single-subject design analysis techniques were used to analyze data, whereby the Cohen's standardized measurement of effect size between RP and FP were determined as $\delta=0.20, \delta=0.50$, and $\delta=0.80$ for small, medium, and large effects, respectivel;. ${ }^{28,29}$ in which a negative outcome represents $\mathrm{RP}<\mathrm{FP}$, and a positive outcome represents RP $>$ FP. Additionally, splitmiddle trend analysis was applied to non-protein oxidation rates to establish trends and trend direction.

\section{Results}

RP resulted in lower TDEE compared with FP (Table 1), possibly associated with greater walking time (Figure 2), lighter pack-weight, and lower starting lean body mass observed on RP. Heart rate (RP $140 \pm 9 \mathrm{bpm}$, FP $136 \pm 16$ bpm; $\delta=0.3$ ), RPE (RP $14 \pm 2$, FP $11 \pm 2 ; \delta=1.2$ ), thermal comfort rating (RP $9 \pm 1$, FP $8 \pm 1 ; \delta=0.6$ ), and $\mathrm{T}_{\mathrm{re}}(\mathrm{RP}$ pre $36.8 \pm 0.4^{\circ} \mathrm{C}$ and post $38.1 \pm 0.4^{\circ} \mathrm{C}$, FP pre $36.7 \pm 0.2^{\circ}$ $\mathrm{C}$ and post $37.8 \pm 0.1^{\circ} \mathrm{C} ; \delta=1.0$ ) were observed to be higher on RP. Relative to Day 1 pre-running, larger reductions in body fat mass, but not nude body mass, were observed on RP, compared with FP (Table 1). 
Table 2. Circulating immune and iron status markers of an ultraendurance runner during a $250 \mathrm{~km}\left(50 \mathrm{~km} \cdot \mathrm{day}^{-1}\right.$ for 5 consecutive days) laboratory simulated multistage ultramarathon (MSUM) in warm conditions in response to rationed (RP) and full (FP) provision.

\begin{tabular}{|c|c|c|c|c|c|c|c|c|c|c|c|c|}
\hline & \multicolumn{2}{|c|}{ Day 1} & \multicolumn{2}{|c|}{ Day 2} & \multicolumn{2}{|c|}{ Day 3} & \multicolumn{2}{|c|}{ Day 4} & \multicolumn{2}{|c|}{ Day 5} & \multirow{2}{*}{$\begin{array}{c}\text { Day } 6 \\
\text { Pre }\end{array}$} & \multirow{2}{*}{$\begin{array}{l}\text { Cohen's } \\
\text { RP vs FP }\end{array}$} \\
\hline & Pre & Post & Pre & Post & Pre & Pre & Pre & Post & Pre & Post & & \\
\hline Leukocyte counts $\left(\times 10^{9} \cdot \mathrm{L}^{-1}\right)$ & & & & & & & & & & & & $0.4^{\dagger}$ \\
\hline $\mathrm{RP}$ & 6.2 & 14.0 & 6.8 & 13.6 & 7.5 & 10.4 & 5.3 & 10.4 & 4.4 & 9.6 & 7.7 & \\
\hline FP & 6.1 & 12.3 & 5.9 & 10.1 & 6.2 & 8.0 & 5.5 & 7.9 & 4.8 & 7.8 & 5.0 & \\
\hline Neutrophil counts $\left(\mathrm{x} 10^{9} \cdot \mathrm{L}^{-1}\right)$ & & & & & & & & & & & & $0.4^{\dagger}$ \\
\hline $\mathrm{RP}$ & 4.4 & 11.5 & 4.8 & 11.2 & 5.3 & 8.0 & 3.2 & 7.7 & 2.9 & 6.6 & 5.7 & \\
\hline FP & 4.2 & 10.3 & 4.2 & 7.8 & 4.0 & 5.8 & 3.5 & 5.5 & 3.0 & 5.6 & 2.7 & \\
\hline Lymphocyte counts $\left(\times 10^{9} \cdot \mathrm{L}^{-1}\right)$ & & & & & & & & & & & & $0.5^{\dagger}$ \\
\hline $\mathrm{RP}$ & 1.2 & 1.3 & 1.3 & 1.5 & 1.5 & 1.6 & 1.2 & 1.8 & 1.0 & 2.0 & 1.2 & \\
\hline FP & 1.3 & 1.1 & 1.1 & 1.5 & 1.5 & 1.4 & 1.3 & 1.5 & 1.2 & 1.5 & 1.6 & \\
\hline Monocyte counts $\left(\mathrm{x} 10^{9} \cdot \mathrm{L}^{-1}\right)$ & & & & & & & & & & & & $0.5^{\dagger}$ \\
\hline $\mathrm{RP}$ & 0.5 & 1.2 & 0.5 & 0.8 & 0.7 & 0.8 & 0.7 & 0.8 & 0.6 & 0.7 & 0.7 & \\
\hline FP & 0.4 & 0.7 & 0.5 & 0.6 & 0.5 & 0.6 & 0.5 & 0.6 & 0.4 & 0.6 & 0.6 & \\
\hline Stimulated elastase release $^{a}\left(\mathrm{ng} \cdot \mathrm{mL}^{-1}\right)$ & & & & & & & & & & & & $0.6^{\dagger}$ \\
\hline $\mathrm{RP}$ & 5229 & - & 4264 & - & 5683 & - & 3030 & - & 5149 & - & 6427 & \\
\hline FP & 5814 & - & 5781 & - & 5316 & - & 5825 & - & 1931 & - & 3751 & \\
\hline Elastase release per cell $\left(\mathrm{fg} \cdot \mathrm{cell}^{-1}\right)^{a}$ & & & & & & & & & & & & $0.6^{\dagger}$ \\
\hline $\mathrm{RP}$ & 570 & - & 514 & - & 680 & - & 595 & - & 1223 & - & 810 & \\
\hline FP & 692 & - & 751 & - & 727 & - & 874 & - & 366 & - & 750 & \\
\hline IL-6 $\left(\mathrm{pg} \cdot \mathrm{mL}^{-1}\right)$ & & & & & & & & & & & & $-0.3^{\dagger}$ \\
\hline $\mathrm{RP}$ & 16.0 & 33.8 & 17.5 & 21.3 & 18.1 & 24.0 & 9.1 & 26.9 & 12.7 & 11.4 & 15.0 & \\
\hline FP & 11.8 & 33.9 & 16.8 & 15.1 & 11.1 & 26.2 & 14.6 & 21.1 & 21.1 & 9.4 & 7.8 & \\
\hline $\mathrm{IL}-1 \beta\left(\mathrm{pg} \cdot \mathrm{mL}^{-1}\right)$ & & & & & & & & & & & & -0.9 \\
\hline $\mathrm{RP}$ & 3.7 & 3.0 & 3.2 & 2.7 & 2.2 & 2.8 & 1.4 & 3.4 & 2.1 & 1.3 & 1.5 & \\
\hline FP & 2.5 & 2.5 & 2.4 & 1.7 & 1.7 & 3.4 & 1.5 & 3.0 & 2.1 & 0.9 & 1.0 & \\
\hline $\mathrm{TNF}-\alpha\left(\mathrm{pg} \cdot \mathrm{mL}^{-1}\right)$ & & & & & & & & & & & & $0.5^{\dagger}$ \\
\hline $\mathrm{RP}$ & 12.8 & 17.8 & 16.2 & 15.2 & 14.6 & 16.3 & 10.8 & 16.4 & 13.2 & 10.6 & 13.9 & \\
\hline FP & 11.3 & 12.1 & 12.3 & 10.2 & 10.3 & 14.4 & 11.8 & 12.8 & 15.5 & 8.0 & 8.8 & \\
\hline $\mathrm{IL}-8\left(\mathrm{pg} \cdot \mathrm{mL}^{-1}\right)$ & & & & & & & & & & & & $0.1^{\dagger}$ \\
\hline $\mathrm{RP}$ & 20.0 & 37.0 & 22.8 & 27.2 & 20.2 & 24.0 & 11.4 & 29.8 & 15.2 & 18.2 & 18.1 & \\
\hline FP & 16.8 & 30.4 & 16.6 & 18.2 & 12.5 & 28.7 & 16.8 & 24.1 & 22.9 & 18.3 & 10.9 & \\
\hline $\mathrm{IL}-10\left(\mathrm{pg} \cdot \mathrm{mL}^{-1}\right)$ & & & & & & & & & & & & $0.3^{\dagger}$ \\
\hline $\mathrm{RP}$ & 11.4 & 188.9 & 18.4 & 60.5 & 17.0 & 26.1 & 12.3 & 27.2 & 11.4 & 15.4 & 16.1 & \\
\hline FP & 2.7 & 71.4 & 6.1 & 21.8 & 5.3 & 12.2 & 5.6 & 9.3 & 5.9 & 12.1 & 2.3 & \\
\hline IL-1ra $\left(\mathrm{pg} \cdot \mathrm{mL}^{-1}\right)$ & & & & & & & & & & & & $0.7^{\dagger}$ \\
\hline $\mathrm{RP}$ & 27.2 & 82.8 & 24.0 & 76.6 & 20.2 & 45.5 & 27.5 & 62.0 & 35.0 & 46.8 & 32.4 & \\
\hline FP & 19.1 & 40.3 & 12.1 & 28.2 & 14.6 & 35.3 & 19.9 & 22.2 & 14.7 & 19.2 & 6.8 & \\
\hline Erythrocyte counts $\left(\mathrm{x} 10^{12} \cdot \mathrm{L}^{-1}\right)$ & & & & & & & & & & & & -0.2 \\
\hline $\mathrm{RP}$ & 5.7 & - & 5.6 & - & 5.7 & - & 5.6 & - & 5.7 & - & 5.9 & \\
\hline FP & 5.4 & - & 5.4 & - & 5.5 & - & 5.4 & - & 5.4 & - & 5.4 & \\
\hline Haemoglobin $\left(\mathrm{g} \cdot \mathrm{L}^{-1}\right)$ & & & & & & & & & & & & $0.4^{\dagger}$ \\
\hline $\mathrm{RP}$ & 176 & - & 176 & - & 176 & - & 176 & - & 176 & - & 179 & \\
\hline FP & 168 & - & 168 & - & 168 & - & 168 & - & 168 & - & 168 & \\
\hline Total iron $\left(\mu \mathrm{mol} \cdot \mathrm{L}^{-1}\right)$ & & & & & & & & & & & & $0.1^{\dagger}$ \\
\hline $\mathrm{RP}$ & 23.0 & - & 28.1 & - & 32.0 & - & 23.0 & - & 17.8 & - & 10.0 & \\
\hline FP & 19.0 & - & 13.6 & - & 14.7 & - & 17.7 & - & 20.1 & - & 21.9 & \\
\hline Total transferrin $\left(\mathrm{g} \cdot \mathrm{L}^{-1}\right)$ & & & & & & & & & & & & $0.00^{\dagger}$ \\
\hline $\mathrm{RP}$ & 2.6 & - & 2.7 & - & 2.7 & - & 2.9 & - & 2.6 & - & 2.7 & \\
\hline FP & 3.0 & - & 3.0 & - & 3.2 & - & 3.1 & - & 3.1 & - & 3.2 & \\
\hline
\end{tabular}


Table 2. (Continued)

\begin{tabular}{|c|c|c|c|c|c|c|c|c|c|c|c|c|}
\hline & \multicolumn{2}{|c|}{ Day 1} & \multicolumn{2}{|c|}{ Day 2} & \multicolumn{2}{|c|}{ Day 3} & \multicolumn{2}{|c|}{ Day 4} & \multicolumn{2}{|c|}{ Day 5} & \multirow{2}{*}{$\begin{array}{c}\text { Day } 6 \\
\text { Pre }\end{array}$} & \multirow{2}{*}{$\begin{array}{l}\text { Cohen's } \delta \\
\text { RP vs FP }\end{array}$} \\
\hline & Pre & Post & Pre & Post & Pre & Pre & Pre & Post & Pre & Post & & \\
\hline Transferrin saturation (\%) & & & & & & & & & & & & $0.3^{\dagger}$ \\
\hline $\mathrm{RP}$ & 35.0 & - & 45.4 & - & 53.7 & - & 36.8 & - & 32.1 & - & 18.7 & \\
\hline FP & 25.0 & - & 18.8 & - & 20.0 & - & 24.0 & - & 27.5 & - & 28.2 & \\
\hline Ferritin $\left(\mathrm{ng} \cdot \mathrm{mL}^{-1}\right)$ & & & & & & & & & & & & $2.0^{\dagger}$ \\
\hline $\mathrm{RP}$ & 115.0 & - & 136.1 & - & 173.8 & - & 180.7 & - & 163.0 & - & 146.1 & \\
\hline FP & 26.0 & - & 31.3 & - & 35.7 & - & 36.5 & - & 31.7 & - & 32.4 & \\
\hline
\end{tabular}

Changes in bone status induced by MSUM on RP or FP were trivial.

Total carbohydrate and fat oxidation substantially decreased $(\delta=-3.9)$ and increased $(\delta=3.7)$, respectively, during running throughout the MSUM on RP, compared with FP (Figure 3). Pre- and post-running blood glucose concentration was constant throughout the MSUM on $\mathrm{RP}\left(5.4 \pm 1.3 \mathrm{mmol} \cdot \mathrm{L}^{-1}\right.$ and $\left.5.7 \pm 0.5 \mathrm{mmol} \cdot \mathrm{L}^{-1}\right)$, and $\mathrm{FP}$ $\left(4.9 \pm 1.6 \mathrm{mmol} \cdot \mathrm{L}^{-1}\right.$ and $\left.5.8 \pm 1.4 \mathrm{mmol} \cdot \mathrm{L}^{-1}\right)(\Delta$ pre- to post-exercise, $\delta=-0.4)$. Plasma cortisol concentration was substantially higher on RP pre- $(\delta=1.6)$ and post- $(\delta=2.0)$ running $\left(626 \pm 111 \mathrm{nmol} \cdot \mathrm{L}^{-1}\right.$ and $\left.591 \pm 132 \mathrm{nmol} \cdot \mathrm{L}^{-1}\right)$, compared with FP $\left(445 \pm 47 \mathrm{nmol} \cdot \mathrm{L}^{-1}\right.$ and $297 \pm 92$ nmol.L $)(\delta=1.7)$. Pre- $(\delta=2.0)$ and post- $(\delta=1.1)$ running urinary acetoacetic acid was substantially higher on RP $\left(1.1 \pm 0.5 \mathrm{mmol} \cdot \mathrm{L}^{-1}\right.$ and $\left.2.0 \pm 1.9 \mathrm{mmol} \cdot \mathrm{L}^{-1}\right)$, compared with FP (no trace).

Despite a small difference for total gastrointestinal symptoms between RP (summation: 236) and FP (268) $(\delta=-0.3)$, RP showed a reduced gut discomfort (87; $\delta=-1.0)$, possibly due to reduced reports of upper-gastrointestinal $(88 ; \delta=-1.0)$ and lower-gastrointestinal (73, $\delta=-0.6)$, compared with FP $(131,168$, and 103, respectively); of which belching and bloating predominated. Nausea was substantially higher on RP $(\delta=1.9)$. Interest in food $(\delta=1.3)$ and appetite $(\delta=1.4)$ were substantially higher on RP compared with FP throughout the MSUM, with no observable difference for interest in drink and thirst $(\delta<0.2)$. Pre- to post-running change in I-FABP was higher $(\delta=0.9)$ on $\mathrm{RP}\left(\Delta 94 \pm 292 \mathrm{pg} \cdot \mathrm{ml}^{-1}\right)$, compared to FP $\left(\Delta-218 \pm 261 \mathrm{pg} \cdot \mathrm{mL}^{-1}\right)$. No change in pre- to postrunning fecal calprotectin was observed throughout the MSUM ( $\Delta$ RP $5 \pm 9 \mu \mathrm{g} \cdot \mathrm{g}^{-1}$ and $\Delta$ FP $8 \pm 11 \mu \mathrm{g} \cdot \mathrm{g}^{-1}$ ). Breath hydrogen increased at $6 \mathrm{~h}$ on RP $(6 \pm 2 \mathrm{ppm})$ and FP $(10 \pm 6 \mathrm{ppm})(\delta=-0.9)$, but remained under clinical reference range $\left(\Delta<10 \mathrm{ppm} v s\right.$. pre-running). ${ }^{31} \mathrm{RP}$ resulted in a modestly higher leukocytosis trafficking, inflammatory profile, and bacterially-challenged neutrophil degranulation, compared with FP (Table 2). Moreover, neutrophil to lymphocyte ratio (a supportive marker of systemic inflammation) was higher pre- $(\delta=1.0)$ and post- $(\delta=0.2)$ running on RP $(3.5 \pm 0.6$ and $5.8 \pm 2.3$, respectively) compared with FP $(2.8 \pm 0.6$ and $5.3 \pm 2.3$, respectively). However, the changes in iron status throughout the MSUM, on RP and FP, remain trivial. Total mood disturbance was substantially higher post-

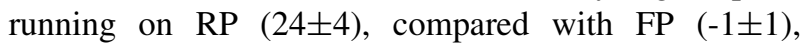
throughout the MSUM. This also included, lower reports of fatigue (RP: $12 \pm 1$, FP: $2 \pm 1$ ) and higher reports of vigor (RP: $7 \pm 2$, FP: $11 \pm 1$ ).

\section{Discussion}

This case study has shown that food provisions catering to target total daily energy expenditure of an ultraendurance runner can be achieved within the pack-weight regulations of self-sufficient MSUM events (eg, $\leq 15.0 \mathrm{~kg}$, Marathon des Sables, Morocco), and were successfully consumed by the subject. It also provides data to suggest that, despite the heavier pack-weight, in the subject of this case-study, RP resulted in greater physiological (ie, stress hormone, leukocyte trafficking, epithelial injury, and cytokinemia) and psychophysiological (mood and perceptive markers of fatigue, feeding and exercise tolerance) disturbances. These outcomes may have contributed to more walking time observed on RP, compared with FP, from Day 3 of running and onwards. It was reported that the $6 \mathrm{~km} \cdot \mathrm{h}^{-1}$ walking on FP corresponded to the eating of the higher portioned savory solid food provided in the third to fourth hour daily, a strategic approach in response to difficulties consuming such food during running. Whereas, the subject reported the variable walking time on RP was due to fatigue and an inability to maintain $55 \% \quad \mathrm{VO}_{2}$ max with the respective lower carrying weight. 
Modestly higher gut discomfort, upper-gastrointestinal symptoms, and malabsorption were observed on FP, possibly associated with the unaccustomed large food volumes, which may be overcome with training the gut. ${ }^{19,30,31}$ However, the high carbohydrate intake rate during running on FP appeared to protect against exercise-associated epithelial injury. ${ }^{16,32}$ From a practical perspective, the subject reported: "on FP, I struggled from Day 1 of running with the volume of food. It then became a constant challenge to eat what was provided during running. Each morning, however, I felt rested and recovered almost to the point where I felt I hadn't run the day before, being both mentally and physically fresh."

It is common for ultraendurance runners to ration food intake to minimize pack-weight, in the belief that a lighter pack will ease the physiological and mental burden of MSUM. Additionally, there is a belief that endogenous fat energy substrate will provide the main fuel source through such events, and thus carrying calories beyond the event's minimum requirements are unnecessary. The current case study shows that food rationing, and subsequently larger energy deficits throughout, irrespective of sufficient endogenous energy reserves, appear not to have been beneficial for the subject. The progressive decline in total carbohydrate oxidation and increased fat oxidation (and increased ketogenesis), with subsequent increases in circulating cortisol and inflammatory cytokines, known for their fatigogenic properties, ${ }^{33}$ may have contributed to the longer walking time and fatigue state observed on RP from Day 3 of running onwards. Moreover, the substantial increase in plasma volume observed on RP (19\%), compared with FP $(6 \%)$, is not explained by the magnitude of thermoregulatory strain exposure (eg, $38.1^{\circ} \mathrm{C}$ post-running $\mathrm{T}_{\mathrm{re}}$ ). ${ }^{34}$ Thus, the osmotic effects of plasma protein or amino acids as a result of exercise-associated gluconeogenesis and (or) rhabdomyolysis may be involved (eg, proteinuria observed Days 2 through 5 of running on RP only). ${ }^{35,36}$ From a practical perspective, the subject reported: " $R P$ was tolerated until Day 3 of running, thereafter I started craving more food. I felt continuously depleted, tired, and not fully recovered at the start of each day. I also got more agitated, and feeling hazy day and night. I underperformed both mentally and physically, irrespective of pack-weight." POMS showed a larger perceptive mood disturbance and fatigue, and low exertional vigor with RP. This response is in accordance with previous field observation, whereby ultraendurance runners report severe hunger and food seeking behavior from Day 3 of running onwards in self-sufficient MSUM events, which corresponded with increased fatigue status. ${ }^{6,7}$ Therefore, catering for energy provisions within gastrointestinal tolerance levels, through meeting carbohydrate and protein requirements firstly, and then supporting with fat dietary sources, may foster a positive approach for the subject in preparation for the desert ultrachallenge. ${ }^{17,37,38}$ The subject reported: "I believe that this experience gave me a better insight into the effects of energy and nutrient requirements in multiday endeavors, " aiding future programming of ultraendurance challenges.

It has previously been shown that iron status progressively depletes in response to consecutive days of prolonged running, due to systemic inflammation-induced hepcidin release, impairing iron absorption, irrespective of iron intake quantity or quality. ${ }^{10}$ Considering the laboratory simulated MSUM resulted in a modest disturbance to systemic cytokine profile, it was surprising that iron state was not perturbed. This may possibly be due to the lower number of consecutive days of prolonged physical exertion then previously reported. ${ }^{10,39}$

It is important to note that within a single-subject design order and carry-over effects are difficult to overcome, and outcomes must be interpreted with caution, especially when translating to the broader ultraendurance population. For example, the subject's baseline body composition, and possibly fitness status, varied between the start of RP and FP. It was also not possible to blind the participant to the feeding intervention (ie, volume of food in RP vs FP) and subsequent pack weight for running protocol. Nevertheless, these limitations are more likely to impact with the subjective markers measured (ie, psychophysiological profile) during the simulated MSUM, which are under the control of the respondent. Whereas, objective biomarkers and metabolic responses are less likely to be influenced by such trial awareness. Acknowledgement must also be given to the static laboratory-control nature of the casestudy, which may not directly mimic the real-life dynamic and on-site adaptive scenario of each individual MUSM event.

In conclusion, after objective assessment of energy expenditure, appropriate dietary programming and food provisions targeting energy requirement was achieved within the pack-weight regulations of self-sufficient MSUM events for the subject. Despite the lighter packweight, the provisions of rationed energy requirements resulted in greater physiological and psychophysiological disturbances associated with physical exertional output in response to a laboratory simulated MSUM, when compared with provisions of full energy requirements Considering the translational outcomes of this current single-subject case study into the ultraendurance mainstream population warrants further investigation, the findings support thorough objective assessment and individual tailored dietary programming for ultraendurance runners participating in self-sufficient MSUM. 
Acknowledgments: The authors thank the subject for participating. The authors acknowledge the contribution of the Monash University Sport \& Exercise Nutritional Support \& Research Team in the collection, processing and analysis of data and samples.

Author contributions: Ricardo Costa (RC) was the chief investigator of this research. RC, Rebekah Alcock (RA), and Alan McCubbin (AM) contributed towards the original research idea and development of the experimental design. RC, RA, AM, and Vera Camões-Costa contributed to the various aspects of data and sample collection and analysis. All authors contributed to the preparation and review of the manuscript. All authors read and approved the final manuscript.

Financial and Material Support: Meals (BASE Essential) to support the nutritional intervention were provided by Monash University, Department of Nutrition Dietetic \& Food, Notting Hill, Victoria, Australia. Pro4mance Global Pty Ltd, Bayswater, Victoria, Australia, provided Produrance for carbohydrate feeding during exercise and Procover for recovery nutrition. The current case-study intervention was supported by the Monash University, Department of Nutrition Dietetic \& Food, Notting Hill, Victoria, Australia.

Disclosures: RC is the intellectual property owner of the BASE Essential meal range, which is currently licensed to The Australia Sports Tech Company Pty Ltd.

\section{References}

1. Hoffman MD, Ong JC, Wang G. Historical analysis of participation in $161 \mathrm{~km}$ ultramarathons in North America. Int J Hist Sport. 2010;27(11):1877-91.

2. Knoth C, Knechtle B, Rüst CA, Rosemann T, Lepers R. Participation and performance trends in multistage ultramarathon - the 'Marathon des Sables' 2003-2012. Extreme Physiol Med. 2012;1(1):13.

3. Burke LM, Ross ML, Garvican-Lewis LA, Welvaert M, Heikura IA, Lepers R, et al. Low carbohydrate, high fat diet impairs exercise economy and negates the performance benefits from intensified training in elite race walkers. J Physiol. 2017;595(9):2785-807.

4. Yeo WK, Carey AL, Burke L, Spriet LL, Hawley JA. Fat adaptation in well-trained athletes: effects on cell metabolism. Appl Physiol Nutr Metab. 2011;36(1):12-22.

5. Pinckaers PJ, Churchward-Venne TA, Bailey D, van Loon LJ. Ketone bodies and exercise performance: The next magic bullet or merely hype. Sports Med. 2017;47(3):383-91.

6. Costa RJ, Swancott AJM, Gill S, Hankey J, Scheer V, Murray $\mathrm{A}$, et al. Compromised energy and macronutrient intake of ultraendurance runners during a multistage ultramarathon conducted in a hot ambient environment. Int J Sports Sci. 2013;3(2):51-62.

7. McCubbin AJ, Cox GR, Broad EM. Case study: nutrition planning and intake for Marathon des Sables - a series of five runners. Int J Sports Nutr Exerc Metab. 2016;26(6):581-7.

8. Costa RJS, Jones GE, Lamb KL, Coleman R, Williams JH. The effects of a high carbohydrate diet on cortisol and salivary immunoglobulin A (s-IgA) during a period of increase exercise workload amongst Olympic and Ironman triathletes. Int J Sports Med. 2005;26(10):880-5.

9. Costa RJS, Oliver SJ, Laing SJ, Waiters R, Bilzon JL, Walsh NP. Influence of timing of postexercise carbohydrate-protein ingestion on selected immune indices. Int J Sports Nutr Exerc Metab. 2009;19(4):366-84.

10. Dempster S, Britton R, Murray A, Costa RJS. Case study: Nutrition and hydration status during $4254 \mathrm{~km}$ of running over 78 consecutive days. Int J Sports Nutr Exerc Metab. 2013;23(5):533-41.

11. Gill SK, Teixeira A, Rama L, Rosado F, Hankey J, Scheer $\mathrm{V}$, et al. Circulatory endotoxin concentration and cytokine profile in response to exertional-heat stress during a multistage ultramarathon competition. Exerc Immunol Rev. 2015;21:114-28.

12. Costa RJS, Teixiera A, Rama L, Swancott AJ, Hardy LD, Lee B, et al. Water and sodium intake habits and status of ultraendurance runners during a multistage ultramarathon conducted in a hot ambient environment. Nutr J. 2013;12:13.

13. Hew-Butler T, Rosner MH, Fowkes-Godek S, Dugas JP, Hoffman MD, Lewis DP, et al. Statement of the Third International Exercise-Associated Hyponatremia Consensus Development Conference, Carlsbad, California, 2015. Clin J Sport Med. 2015;25(4):303-20.

14. Costa RJS, Snipe R, Camões-Costa V, Scheer BV, Murray A. The impact of gastrointestinal symptoms and dermatological injuries on nutritional intake and hydration status during ultramarathon events. Sports Med Open. 2016;2(16):1-14.

15. Stuempfle KJ, Hoffman MD. Gastrointestinal distress is common during a 161-km ultramarathon. J Sports Sci. 2015;33(17):1814-21.

16. Costa RJS, Snipe R, Kitic C, Gibson P. Systematic review: Exercise-induced gastrointestinal syndrome- Implication for health and disease. Alim Therap Pharmacol. 2017;46 (3):246-65.

17. Thomas DT, Erdman KA, Burke LM. American College of Sports Medicine joint position statement. Nutrition and athletic performance. Med Sci Sports Exerc. 2016;48 (3):543-68.

18. Costa RJS, Harper-Smith AD, Oliver SJ, Walters R, Maassen N, Bilzon JLJ, et al. The effects of two nights of sleep deprivation with and without energy restriction on selected immune responses at rest and in response to cold exposure. Eur J Appl Physiol. 2010;109(3):417-28.

19. Costa RJS, Miall A, Khoo A, Rauch C, Snipe R, CamõesCosta V, et al. Gut-training: The impact of two weeks repetitive gut-challenge during exercise on gastrointestinal status, glucose availability, fuel kinetics, and running performance. Appl Physiol Nutr Metab. 2017;42(5):547-57.

20. Britton R, Dempster S, Moore JP, Costa RJS. The use of triaxial accelerometry to support dietary intervention during a multistage mountain ultramarathon: A case study approach. J Sports Sci. 2010;29: S132.

21. Costa RJS, Gill SK, Hankey J, Wright A, Marczak S. Perturbed energy balance and hydration status in ultraendurance runners during a $24 \mathrm{~h}$ ultramarathon. Br J Nutr. 2014;112(3):428-37.

22. Costa RJS, Walters R, Bilzon JLJ, Walsh NP. Effects of immediate post-exercise carbohydrate ingestion with and 
without protein on neutrophil degranulation. Int J Sports Nutr Exerc Metab. 2011;21(3):205-13.

23. McNair D, Lorr M, Droppleman L. Manual for the profile of mood states. San Diego: Educational and Industrial Testing Service. 1971.

24. Bengtsson M, Persson J, Sjölund K, Ohlsson B. Further validation of the visual analogue scale for irritable bowel syndrome after use in clinical practice. Gastroenterol Nurs. 2013;36(3):188-98.

25. Tuck CJ, Ross LA, Gibson PR, Barrett JS, Muir JG. Adding glucose to food and solutions to enahance fructose absorption is not effective in prevneting fructose induced functional gastrointestinal symptoms: randomised controlled trials in patients with fructose malabsorption. $J$ Hum Nutr Diet. 2017;30(1):73-82.

26. Péronnet F, Massicotte D. Table of nonprotein respiratory quotient: an update. Can J Sport Sci. 1991;16(1):23-9.

27. Dill DB, Costill DL. Calculation of percentage changes in volumes of blood, plasma, and red cells in dehydration. $J$ Appl Physiol. 1974;37(2):247-8.

28. de Vries RM, Morey RD. Bayesian hypothesis testing for single-subject designs. Psych Methods. 2013;18(2):165-85.

29. Camões-Costa V, Erjavec M, Horne PJ. The impact of body-part-naming training on the accuracy of imitative performances in 2- to 3-year-old children. J Exp Analysis Beh. 2011;96(3):291-315.

30. Bate JP, Irving PM, Barrett JS, Gibson PR. Benefits of breathhydrogen testing after lactulose administration in analysing carbohydrate malabsorption. Eur J Gastroenterol Hepatol. 2010;22(3):318-26.

31. Miall A, Khoo A, Rauch C, Snipe RMJ, Camões-Costa V, Gibson P, et al. Two weeks of repetitive gut-challenge reduces exercise associated gastrointestinal symptoms and malabsorption. Scand J Med Sci Sports. 2018;28(2):630-40.

32. Snipe R, Khoo A, Kitic C, Gibson P, Costa RJS. Carbohydrate and protein intake during exertional-heat stress ameliorates intestinal epithelial injury and small intestine permeability. Appl Physiol Nutri Metab. 2017;42(12):1283-92.

33. Smith LL. Cytokine hypothesis of overtraining: a physiological adaptation to excessive stress. Med Sci Sports Exerc. 2000;32(2):317-31.

34. Costa RJS, Crockford MJ, Moore JP, Walsh NP. Heat acclimation responses of an ultraendurance running group preparing for hot desert based competition. Eur J Sport Sci. 2014;14(S1):S131-41.

35. Chlíbková D, Knechtle B, Rosemann T, Tomaskova I, Novotny J, Zakovska A, et al. Rhabdomyolysis and exercise-associated hyponatremia in ultra-bikers and ultra-runners. J Int Soc Sports Nutr. 2015;12: 29.

36. Hoffman MD, Stuempfle KJ, Sullivan K, Weiss RH. Exercise-associated hyponatremia with exertional rhabdomyolysis: importance of proper treatment. Clin Nephrol. 2015;83(4):235-42.

37. Churchward-Venne TA, Holwerda AM, Phillips SM, van Loon LJ. What is the optimal amount of protein to support post-exercise skeletal muscle reconditioning in the older adult. Sports Med. 2016;46(9):1205-12.

38. Stellingwerff T, Cox GR. Systematic review: carbohydrate supplementation on exercise performance or capacity of varying durations. Appl Physiol Nutri Metab. 2014;39 (9):998-1011.

39. Fallon KE. Screening for haematological and iron related abnormalities in elite athletes -analysis of 576 cases. J Sci Med Sport. 2008;11(3):329-36. 